\title{
EL CASO DE LAS CAÑADAS DEL ÁREA METROPOLITANA DE BUCARAMANGA
}

Articulación de pensamiento, diseño y acción para la construcción de la Ciudad Sostenible a través de la reivindicación de la estructura ecológica principal. La acumulación de antecedentes fragmentarios entre el hombre y la naturaleza

Alejandro Murillo Salguero*

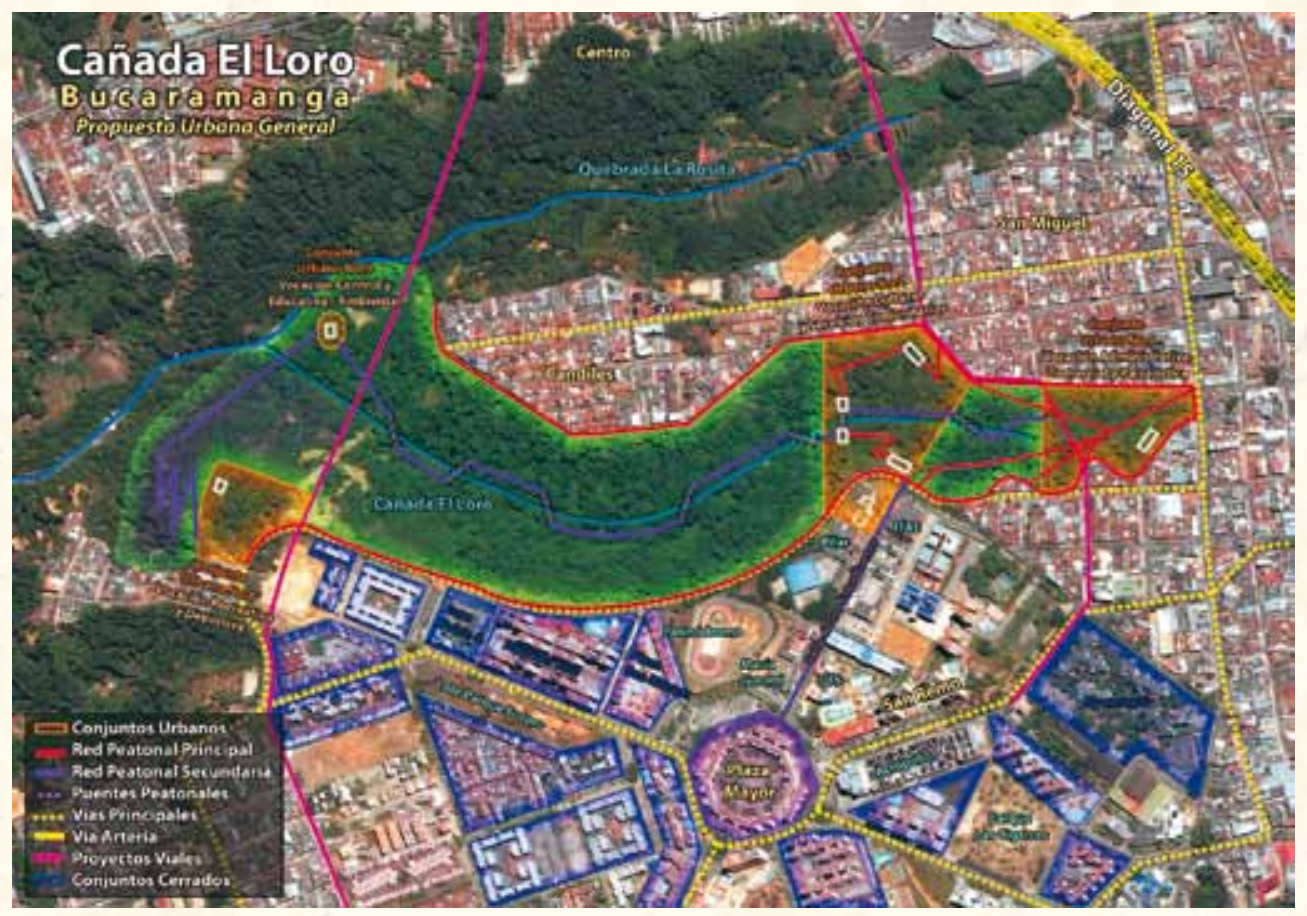

\section{RESUMEN}

La fragmentación histórica de la relación entre el medio ambiente natural y los habitantes de las ciudades, ha generado una profunda problemática ecológica, urbana y social. Las causas, a partir de la ausencia de planificación integral, precaria educación comunitaria y especulación economicista sobre el territorio, han establecido afectaciones negativas generalizadas para los cuerpos hídricos estructurantes del Área Metropolitana de Bucaramanga y los ciudadanos que las viven cotidianamente. Producto de esta condición la Autoridad Ambiental y El Laboratorio de Proyectos Urbanos Citu Experiencia Local establecieron un proceso de investigación participativa con el objetivo de generar conocimiento y proyectar alternativas de resolución de la patología. La estrategia fue desarrollada a partir de la selección de cinco quebradas como experimento piloto para promover un Diseño Urbano Sostenible como alternativa vital.

\section{PALABRAS CLAVE}

Ciudad Sostenible - Desarrollo Urbano Integral - Participación Comunitaria - Estructura Ecológica Principal - Hábitat - Acción Interinstitucional - Prospectiva 


\section{THE CREEKS CASE OF BUCARAMANGA'S \\ METROPOLOTAN AREA \\ Design and action to build a sustainable city through restoration of the main ecological structure:}

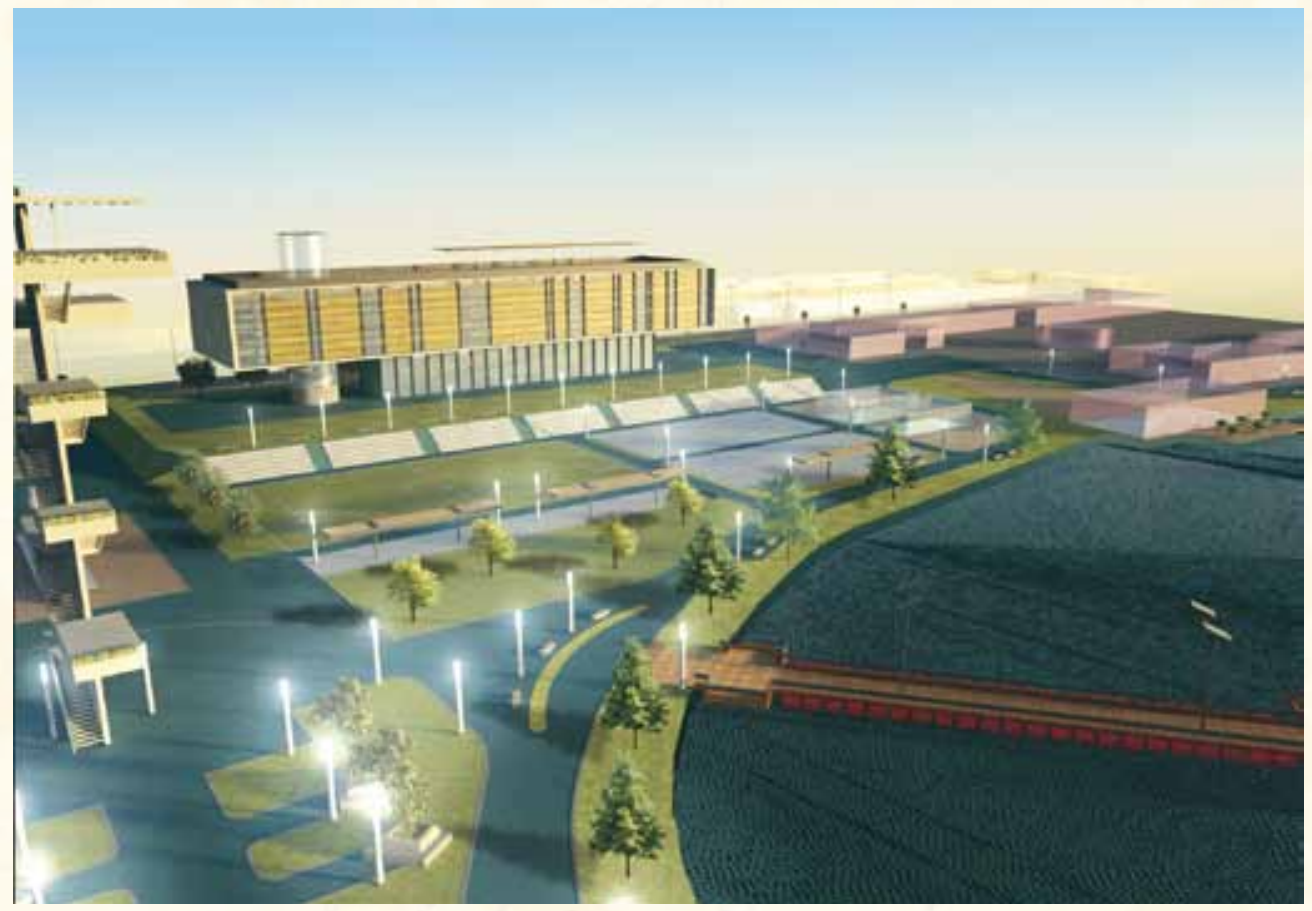

Arquitecto USTA,2004. Pertenece al Laboratorio de Proyectos Urbanos "Citu Experiencia Local" En la ciudad de Bucaramanga. Como integrante del Laboratorio ha desarrollado proyectos interdisciplinarios de interés público relacionados con problemáticas en materia de Equipamientos Urbanos, Arquitectura, Medio Ambiente, $\mathrm{Pa}$ trimonios Locales y Espacio Público. También ha sido ponente en diferentes eventos de debate urbano y autor de publicaciones relacionadas con la ciudad, el diseño urbano, la cultura y la arquitectura.

\begin{abstract}
The historic fragmentation between the environment and the cities' community has generate a deep ecological, urban and social problems as a result of an absent integral planning process, precarious comity education and the territory economic speculation, this problems have established negative affectations over the hydrographic structure located in Bucaramanga's Metropolitan Area and its community. Based in this condition The Environmental Authority and the Urban Projects Lab (CITU) Local Experience have established a participative investigation process to generate knowledge and to project proposals to mitigate the existing problem. The strategy was developed based on the selection of 5 (five) creeks as a leading experiment to promote a Sustainable Urban Design as a relevant alternative.
\end{abstract}

\section{KEY WORDS}

Sustainable City - Integral Urban Development - Communitarian participation - Meaning Environmental configuration - Habitat - Interdisciplinary work - Prospective 
Indistintamente de las características propias de cada proceso de ocupación del territorio para la conformación de las actuales ciudades colombianas, generalmente existió la conciencia básica de parte de sus primeros habitantes en torno a asegurar funcionalidades $y$ conveniencias geográficas del lugar en donde se implantaba el proyecto de asentamiento. Estas condiciones se derivaron a partir de la existencia de recursos naturales renovables y no renovables que suponían riqueza para reducidos sectores de la naciente población, generalmente españoles y algunos nativos que progresivamente cedieron a sus demandas $y$ escalaron posiciones en las estructuras de poder y pertenencia. Las implantaciones genéricas de los poblados tenían marcadas coherencias en relación a los patrimonios ambientales más próximos que aseguraban altos niveles de bienestar y hacían presumir grandes reservas de recursos para el futuro. Los ríos, quebradas, cañadas, planicies, terrazas, lagos y mares fundamentaban las posibilidades de desarrollo a través del comercio, el autoabastecimiento, el transporte e incluso a través de las experiencias sensoriales del contacto de estas fuentes con el ser humano.

El panorama inicial de grandes reservas ambientales, progresivamente ocupadas por el hombre y sus derivaciones materiales, se convirtió en una sumatoria de afectaciones que con el paso de los siglos derivaron en los conglomerados urbanos una alta complejidad de relaciones entre lo que las personas ejecutaron para materializar sus imaginarios de progreso y los costos ambientales que tuvieron que pagarse para lograrlos (Ver Foto I).

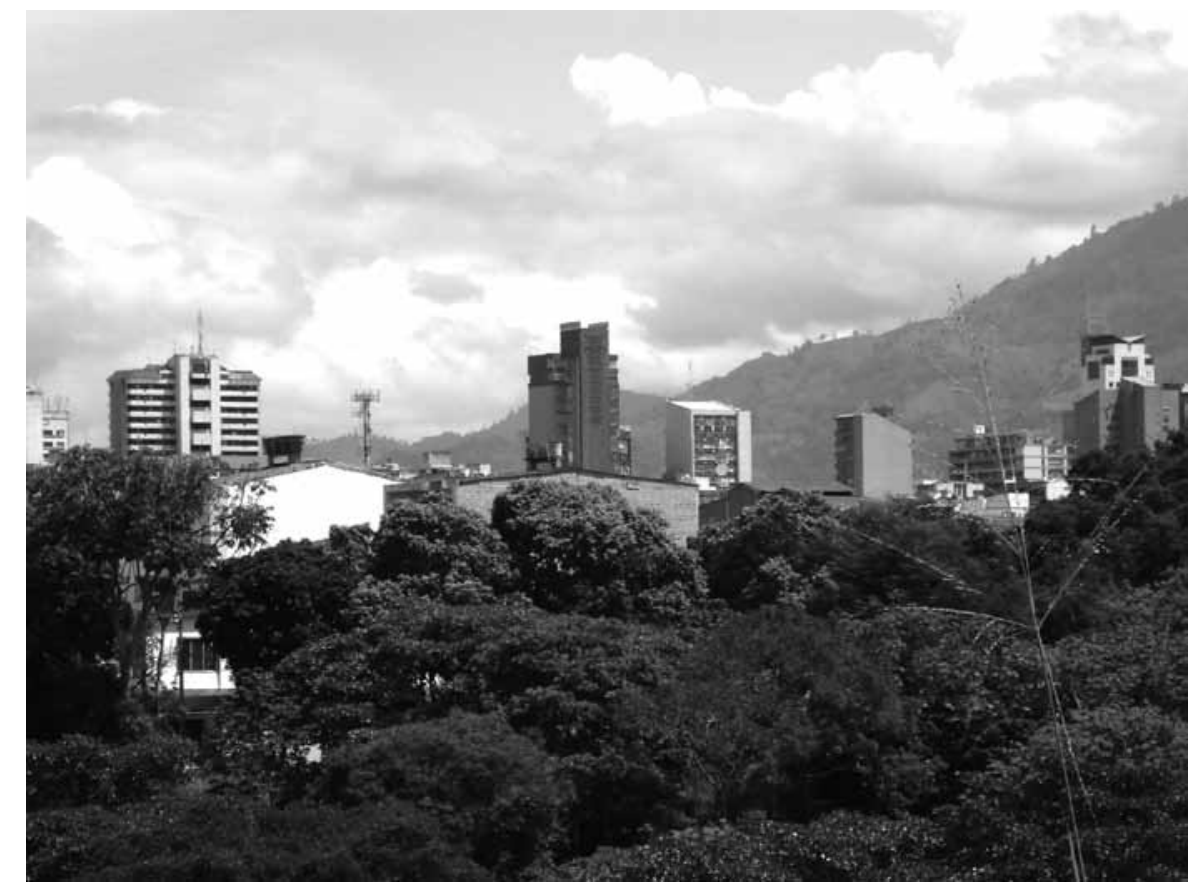

foto I. Contraste entre el bosque urbano que supone la Quebrada el Loro y el paisaje urbano de Bucaramanga.

De la misma manera, este permanente "enfrentamiento" del hombre con su entorno generó para la ciudad de Bucaramanga una huella ambiental desajustada que se manifiesta en el estado actual de deterioro de los patrimonios naturales principales. Se presenta hoy un territorio completamente urbanizado, sin ningún balance entre los volúmenes existentes, la densidad poblacional y la disponibilidad del terreno. La urbanización desborda los límites lógicos de implantación, al instalarse también en terrenos de escarpa, zonas de 
erosión y rondas de protección de ríos y quebradas. Las amenazas por deslizamiento e inundación caracterizan un gran componente de la ciudad. Generalmente este componente son asentamientos de carácter subnormal, nacidos debido a las condicionantes políticas y socioeconómicas de la historia nacional, que proyectan impactos altamente negativos para el ecosistema a través de sistemas espontáneos de alcantarillado y manejo de residuos, y generan una reacción patológica en la calidad de vida de las personas que habitan estos sectores, principalmente en materia de salud. A esta condición se suma la desarticulación de los servicios urbanos centrales con la periferia, en un gradiente que va desde lo barrial hasta lo metropolitano, y pasa por escalas zonales y municipales que articulan equipamientos, servicios de transporte, oportunidades de educación y trabajo así como experiencias humanas fundamentales en los espacios públicos estructurantes.

Como elemento agregado, la visión netamente económica del manejo del espacio y la ordenación del territorio en el Área Metropolitana de Bucaramanga, condenó las fuentes hídricas a un proceso de alta contaminación y desaparición por el vertimiento de residuos y la desidia cívica e institucional. Se presenta hoy un complejo cuadro patológico en el estado de los principales ríos de afectación directa de las dinámicas sociales, ambientales, espaciales y culturales, así como una legitimación del hecho de haber convertido las cañadas y quebradas en improvisadas y monumentales cloacas urbanas. El reto para recuperar las cañadas y quebradas de la contaminación, así como los Ríos de Oro, Frío y Suratá, es un aspecto prioritario en las agendas de las autoridades municipales y ambientales, así como de todas las empresas de relación directa o indirecta con sus cauces y dinámicas generales. (Ver Foto 2)

"Los cuerpos de agua son elementos naturales del espacio público que consolidan y estructuran claramente la ciudad y que representan un valor escénico por cuanto realzan y embellecen su paisaje. En el caso de los ríos, su aprovechamiento para el beneficio urbano demanda la protección de su cuenca en el área de su nacimiento fuera del perímetro urbano; por otra parte la preservación ecológica y la utilización social de su ronda dentro de la ciudad propiamente dicha y la preservación contra la contaminación".'

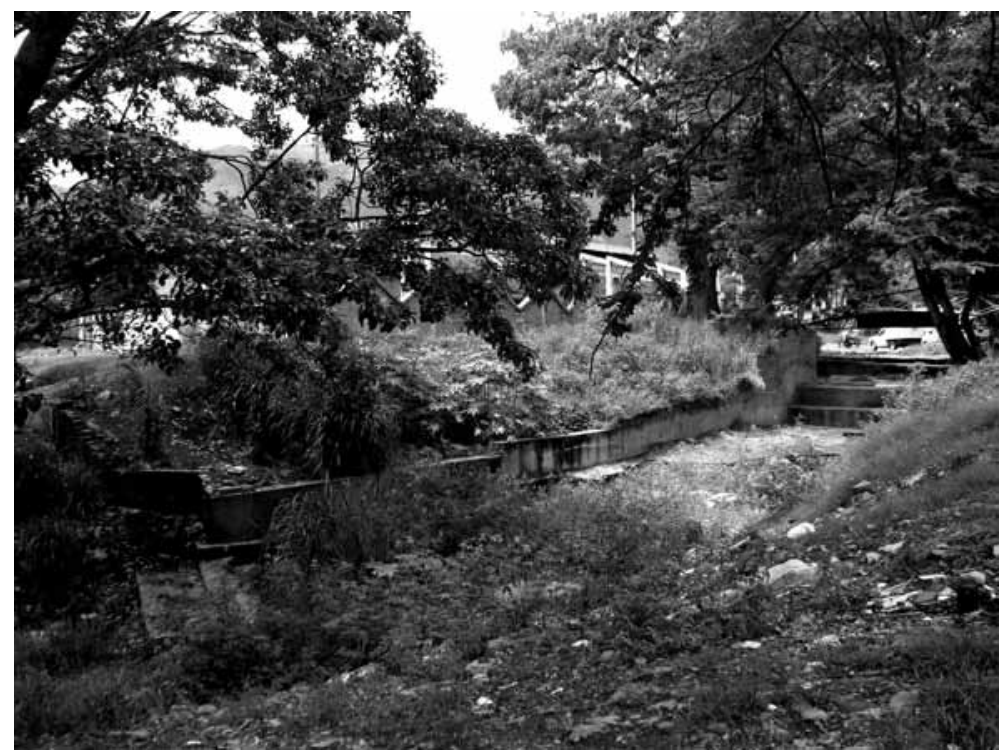

Foto 2. Deterioro de la desembocadura de la Quebrada las Nieves de Girón con el Río de Oro 
2 HOUGH, Michael. "Naturaleza y Ciudad. Planificación Urbana y Procesos Ecológicos". Barcelona: Editorial GG, 1998. p. 6
Surge así el reto fundamental de reivindicar la visión y estimular el cambio del comportamiento de todos los actores sociales, administrativos, políticos, económicos, culturales y ambientales de la ciudad frente al futuro de la Estructura Ecológica Principal, como pivote articulador en la reivindicación de un nuevo modelo que per mita establecer una comunión más acertada entre el hombre contemporáneo y las deudas de recuperación de la naturaleza, para incrementar los niveles de calidad de vida de toda la comunidad (Ver Foto 3).

"El habitante urbano medio, al ocuparse de los asuntos cotidianos, experimenta la ciudad a través de sus trazados de calles y caminos peatonales (...) Sin embargo hay otro paisaje generalmente ignorado que yace bajo la superficie de los diferentes lugares."2

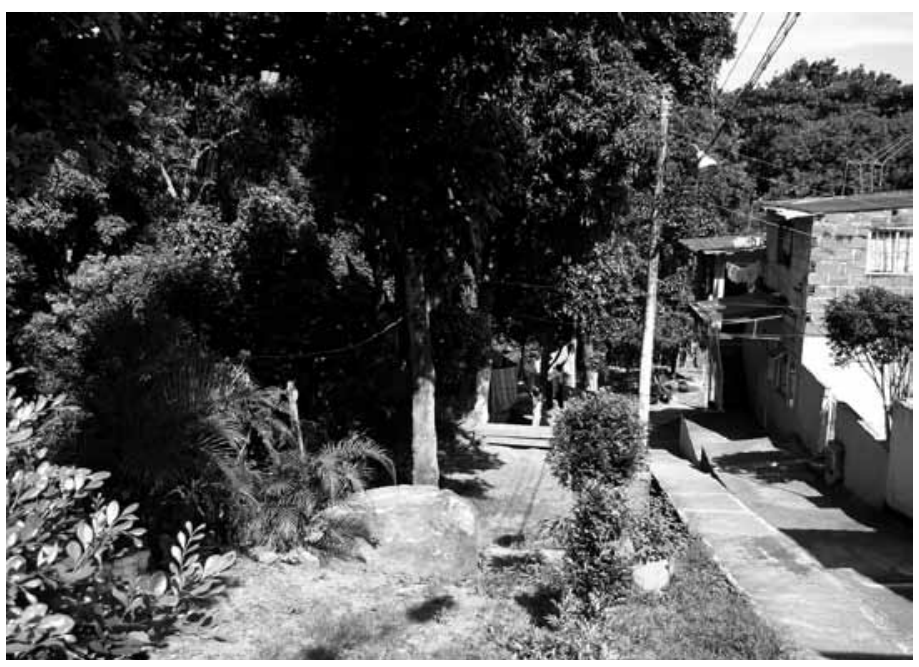

Foto 3. Relación directa de la Cañada La Esperanza con las dinámicas cotidianas de los barrios circundantes

Simultáneamente y como insumo de posibilidades de acción institucional y de flujo e intercambio de conocimiento, recursos, procesos y experiencias, los países del mundo se encuentran identificados en un frente común hacia la atención del medio ambiente como el patrimonio básico que asegurará el bienestar de las generaciones futuras; éstas, principalmente urbanas. Los antecedentes oficiales provienen del Club de Roma (1968) y la Declaración de Estocolmo (1972), en donde, por primera vez, se pone de manifiesto la intención de regular el crecimiento económico desmedido y asumir los temas del medio ambiente como prioritarios para posibilitar plataformas coherentes de Desarrollo Humano. Años después y desde la Comisión Bruntland de las Naciones Unidas en 1987, se generó el primer manifiesto mundial de abordaje hacia el Desarrollo Sostenible, que fue definido como "el que satisface las necesidades del presente sin comprometer la capacidad de las generaciones futuras de satisfacer las propias". De la misma manera al paradigma de la dimensión ambiental como prenda de desarrollo de este postulado a través de la historia y sus derivaciones principalmente ecológicas, se articularon las dimensiones económica y social como fundamentales para establecer un balance real de posibilidades de vida digna y justa para todos los procesos humanos vitales que principalmente se experimentan en las ciudades. 
Así pues, la ciudad enfrenta uno de sus mayores retos, que tiene que ver con la conservación de la vida de los habitantes, y posteriormente, la articulación efectiva y coherente de los patrimonios naturales con los procesos de ocupación del territorio. La falta de una planeación urbana que trascienda los documentos teóricos e institucionales y que contenga visiones concertadas de desarrollo de ciudad, ha generado grandes abismos entre la naturaleza y los conglomerados urbanos y ha profundizado graves problemáticas que, en la actualidad se presentan en medio de un abanico de imposibilidad de cobertura administrativa, técnica, presupuestal y de apropiación ciudadana para la corrección, preservación y proyección. Como elementos adjuntos, el imaginario de progreso basado en la cultura mediática y la inercia economicista que influye el crecimiento desmedido de la ciudad bajo el pilar exclusivo de los rendimientos monetarios (que dibujan un paisaje urbano sin esencia ni realidad), incrementan la distancia para conseguir rangos mínimos de bienestar en medio de la satisfacción de las dimensiones humanas y urbanas básicas.

"Se considera que con el dinero se pueden resolver todos los problemas, por ello no reconoce la importancia de aceptar los recursos no renovables como vitales y de un costo incalculable. Esta visión monetaria no contribuye en nada para articular el crecimiento económico al equilibrio ambiental."”

De esta manera se deja de lado cualquier tipo de emprendimiento interinstitucional hacia el entendimiento y la acción sobre los problemas prioritarios de la ciudad en su estructura fundamental, de comunión del hombre con el entorno natural que habita y los procesos viables de desarrollo a partir de la interacción estratégica de sus competencias como ser vivo que hace parte de otra estructura de ecosistemas relacionados e íntimamente dependientes.

Este panorama, enfrentado a la base académica, técnica, empresarial, comunitaria e institucional del Área Metropolitana de Bucaramanga, sugiere un diálogo urgente hacia la acción estratégica que por medio de la ética de la responsabilidad dirija todos sus esfuerzos para ajustar las deudas históricas que la conformación de la ciudad presenta y por las cuales están en riesgo las posibilidades de vida digna de múltiples grupos poblacionales en el futuro. Es deber de estos grupos humanos conocedores y administradores, posibilitar hojas de ruta claras para la identificación, análisis, diagnóstico, proposición, ejecución, evolución y seguimiento de procesos que atiendan las múltiples expresiones del fraccionamiento del hombre, la ciudad y la naturaleza.

La urgencia en la acción efectiva proveniente de la investigación rigurosa y de la dinámica de mejoramiento de calidad, radica en que la patología crece permanentemente, desvirtúa las lecturas aplazadas o desactualizadas de fenómenos cambiantes y que han estado sometidos a verdades congeladas y a vacíos de acción, que incrementan la incertidumbre sobre sus formas de abordaje y demuestran la inexperiencia y la falta de referentes exitosos para soportar estudios y planes de intervención sobre la problemática en cuestión.

"La ecología y la biología ambiental han sido poco y mal comprendidas por los proyectistas; en muchos casos, esa deficiente comprensión ha conducido a importantes e irreparables daños medioambientales, que podrían haberse previsto a tiempo. De ahí se deduce que si el proyectista establece unas hipótesis iniciales erróneas acerca del medio ambiente y del sistema proyectado, el resultado futuro será una cierta disonancia en el contacto entre el sistema proyectado y su ambiente". ${ }^{4}$
3 CUESTA, Andrés. "Espacio Público y Desarrollo Sostenible". Bogotá: Universidad La Salle, 2003. p. 15 
4 YEANG, Ken. "Proyectar con la naturaleza. Bases ecológicas para el proyecto arquitectónico". Barcelona: Editorial GG 1999. p. 3

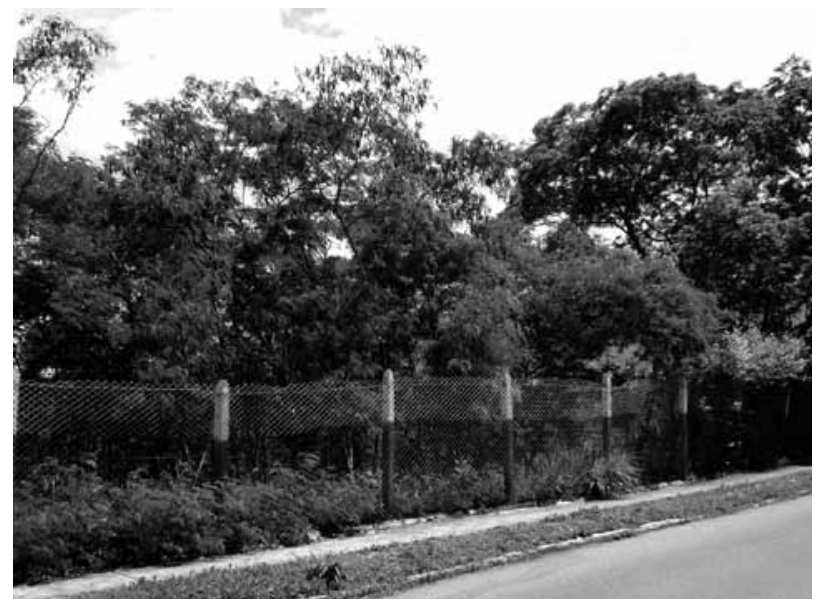

Foto 4 El encerramiento como estrategia de protección ambiental pero de negación de los patrimonios ambientales

El Área Metropolitana de Bucaramanga se encuentra en medio de la complejidad, por desatención, de una patología urbana de fragmentación entre sus recursos naturales y los asentamientos regulares e irregulares que históricamente se han establecido en torno a los ríos y cañadas (Ver foto 4). La ciudad que se ha conformado contiene los antivalores de la dispersión y la negación de sus componentes intrínsecos y sus relaciones directas e indirectas con el entorno. Metropolitanamente se comparte el eje fundamental del Río de Oro, el Río Frío y el Río Suratá, así como la existencia de 42 cañadas de influencia urbana en donde habitamos más de un millón de personas.

A partir de una conciencia contemporánea y como respuesta responsable de la autoridad ambiental de 13 municipios de Santander, incluida el Área Metropolitana de Bucaramanga, la Corporación Autónoma para la Defensa de la Meseta de Bucaramanga (CDMB), planteó el siguiente interrogante que daría paso a un proceso de investigación con el Laboratorio de Proyectos Urbanos CITU EXPERIENCIA LOCAL:

¿La implementación de procesos de intervención ínter-institucional e ínterdisciplinaria en un abordaje de estudio y acción efectiva sobre cinco cañadas piloto del Área Metropolitana, generará posibilidades de implementar políticas, planes y proyectos concretos para la recuperación del Sistema Ecológico Principal en una visión integrada de relaciones ambientales, culturales, sociales, políticas y urbanísticas?

\section{Un adecuado entendimiento del problema para la toma de decisiones de investigación y acción para el desarrollo urbano integral}

En el mes de Febrero del año 2008, la Corporación Autónoma para la Defensa de la Meseta de Bucaramanga (CDMB), realizó una convocatoria abierta a todos los actores involucrados al pensamiento y proyección de la ciudad, para nutrir por medio de una programación establecida, el Proyecto Institucional de "Ciudad Sostenible", que tuvo como punto de partida el encuentro de estos actores en comités de opinión calificada durante varios meses. Producto de estos encuentros de debate, moderados por expertos en prospectiva territorial y bajo las premisas y políticas de la CDMB como autoridad ambiental, se generó una visión preliminar del Área Metropolitana de Bucaramanga hacia el año 2030, habida cuenta de las dimensiones humanas, urbanas y ambientales interrelacionadas hacia la calidad de vida de los habitantes y como prenda de aseguramiento de un desarrollo sostenible del territorio. 
A partir de allí se derivaron propuestas e iniciativas para que por medio de proyectos estratégicos, se lograra avanzar en la generación de conocimiento frente a las diversas vertientes temáticas de Ciudad Sostenible, ya que la certificación de la investigación como mecanismo eficiente para iniciar los procesos de reivindicación urbana y ambiental fue una de las conclusiones fundamentales de la primera fase de los comités interinstitucionales.

Como esfuerzo de priorización y establecimiento de una agenda fundamentada en retos urgentes de abordaje, la CDMB junto al Laboratorio de Proyectos Urbanos CITU EXPERIENCIA LOCAL, generaron un diálogo que condujo a la formalización del ejercicio de estudio y proposición sobre el tratamiento de la Estructura Ecológica Principal del Área Metropolitana de Bucaramanga, focalizado en sus cuerpos de agua y representado en las quebradas y cañadas de influencia urbana del Área Metropolitana de Bucaramanga.

Insertados dentro del Proyecto Institucional de "Mejoramiento de la Cultura Ambiental Ciudadana" y bajo los pilares de la "Coordinación Interinstitucional y la Participación Ciudadana", se fundamentó y engranó la investigación mediante el uso de los insumos y dinámicas permanentes de la CDMB. A través de la línea de acción de "Espacio Público" y por medio de la política de calidad de "Generación de Conocimiento e Investigación Ambiental”, CITU EXPERIENCIA LOCAL y la CDMB concertaron el objetivo del proyecto de investigación, que tuvo, además, la responsabilidad de ser parte de los primeros esfuerzos científicamente concretos sobre las realidades estructuradas en la aspiración de la Ciudad Sostenible hacia el año 2030 que firmaron la CDMB junto con el Ministerio de Ambiente, Vivienda y Desarrollo Territorial, la Gobernación de Santander, las Alcaldías del Área Metropolitana de Bucaramanga e instituciones relacionadas.

El objetivo se planteó asi:

"Generar un proceso de Investigación Participativa por medio de una visión interdisciplinaria que a través de una metodología de documentación, diagnóstico, proposición y socialización, sirva de instrumento de conocimiento, conciencia y emprendimiento interinstitucional hacia la re-estructuración ambiental, urbana y social de cinco cañadas del Área Metropolitana de Bucaramanga como experimento piloto".

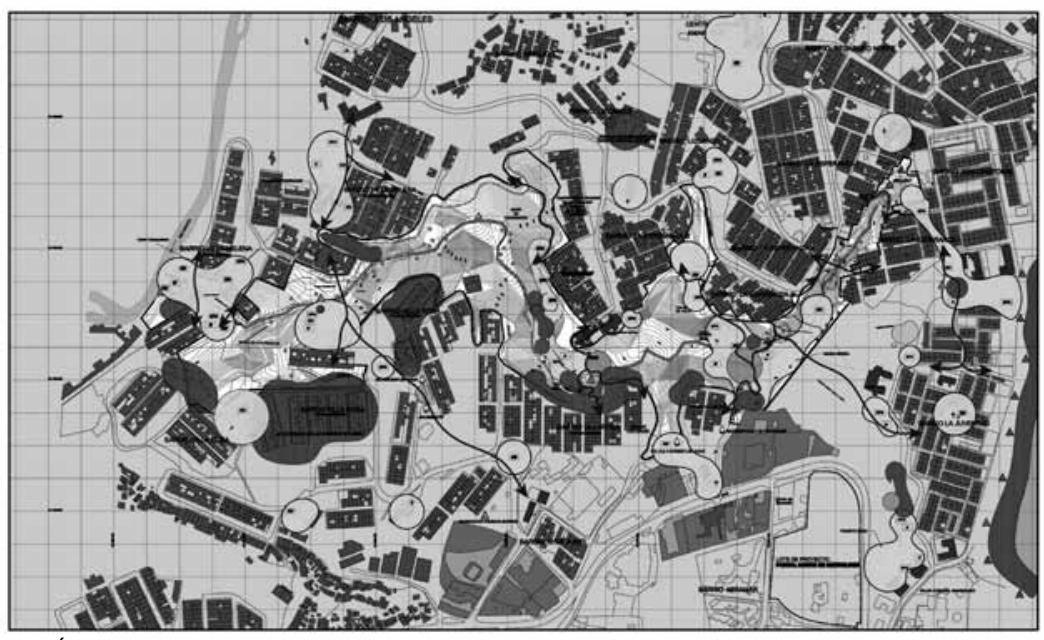

ANÁLISIS DE COMPORTAMIENTO AMBIENTAL: Los senderos trazados formalmente por la comunidad son lugares de alta contaminación. No existen canecas ni mobiliario urbano que posibilite el aseo urbano en ellos. Todo esto se suma a conexiones erradas de algunos barrios, escombretas y residuos sólidos que son arrojados sobre las inmediaciones de la Cañada La Esperanza. 
Para generar una cobertura metropolitana y tener la posibilidad de analizar todos los contextos urbanos, sociales y ambientales e interrelacionarlos, se seleccionaron:

- La Cañada La Esperanza, ubicada en la Comuna 2, Sector Norte de Bucaramanga y que impacta barrios como La Esperanza, Villa Rosa, Villa Helena, Nuevo Horizonte y San Cristóbal. (Ver Plano I)

- En la meseta también se eligió la Quebrada El Loro, un bosque urbano potencial ubicado entre los barrios San Miguel, Candiles, Gómez Niño y la Ciudadela Real de Minas.

- En Floridablanca la Cañada seleccionada fue La Calavera, que nace en Altos de Bellavista y termina en su unión con la Quebrada Zapamanga, atraviesa los barrios Guanatá, Escoflor, Lagos I, Cañaveral y Valencia. (Ver Plano 2)

- Para el caso de Girón la Quebrada objeto de estudio fue Las Nieves, a partir del barrio Altos de La Campiña hasta su desembocadura en el Río de Oro, sector de la Plaza de Mercado Municipal, desarrollándose fundamentalmente en el Centro Histórico y Patrimonial.

- Finalmente, en Piedecuesta la Quebrada elegida fue La Palmira, que nace desde la reserva ambiental posterior del ICP, atraviesa la autopista a Bogotá y pasa por los barrios La Argentina, Palermo, Cataluña y varios conjuntos residenciales cerrados.

El proceso metodológico general se estructuró a partir de una fase de conceptualización, documentación y estudio de referentes desde la perspectiva del Desarrollo Sostenible, la Planeación Urbana Integral, el Desarrollo Humano, las relaciones del medio ambiente con el hombre y la participación social como prenda de conformación legítima de la ciudad libre y diversa, así se formaliza el discurso teórico y la base epistemológica del problema.

La segunda instancia contempló el diagnóstico específico de la realidad urbana, social y ambiental por medio de dos estrategias: Los inventarios físico-estructurales y los análisis socio-geográficos en tres categorías (relaciones funcionales, comportamiento ambiental y sentimientos de afecto, odio e indiferencia frente al espacio). Este proceso se estableció al cruzar las variables de relación entre el pasado, el presente y el futuro por medio de la participación de la comunidad en medio de grupos focales, entrevistas semi-estructuradas y algunos atributos de la Cartografía Social.

"La reconsideración de los problemas de la ciudad a través de la óptica del análisis urbano debe pasar por una refundamentación del significado del plano desde su contenido y utilidad". ${ }^{5}$

5 LEONEL, Francisco Javier. "Del derecho a la ciudad y su sentido dentro del espacio público como experiencia vivencial". Bogotá: Universidad Piloto de Colombia, 2005. p.76

La tercera etapa contempló la generación de propuestas de articulación de componentes de mejoramiento urbano, ambiental y social hacia la generación de escenarios de vida digna, que fueron sustentados rigurosamente desde el diagnóstico y generaron una planimetría de síntesis por medio de un Plan Urbano Integral que remite coherentemente a estrategias y recomendaciones de reivindicación y retejido de las relaciones ambientales y sociales con el entorno que se plantea a partir del Diseño Urbano Sostenible. 


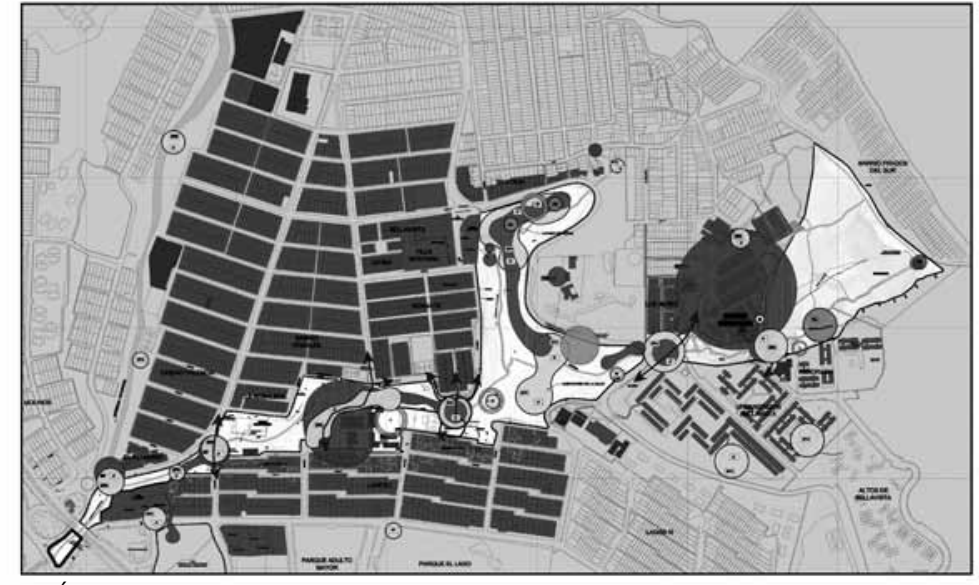

ANALISIS DE COMPORTAMIENTO AMBIENTAL: La Cañada en términos globales padece de un alto grado de contaminación por residuos sólidos que son abandonados en basureros improvisados. De la misma manera, las conexiones erradas, la espontaneidad social que permite tener animales, invadir espacios públicos y atentar contra las especies de flora y fauna complementan el panorama negativo.

El agua, a lo largo del trazado natural también presenta alto grado de patologías

Foto 6. Plano Sociogeográfico de Comportamiento Ambiental - Cañada La Calavera, Floridablanca

El proceso de diagnóstico se desarrolló a través del trabajo de campo y junto con estudios de carácter normativo (Planes de Desarrollo, Planes de Ordenamiento Territorial, Normas Geotécnicas, Estudios de Amenaza e inundación), estudios de referentes nacionales e internacionales de similitud con el ejercicio para establecer los procesos propios de la cultura y la geografía metropolitana y de modelos urbanos, se pudo conocer que la situación actual de las quebradas y cañadas del $A M B$ es altamente patológica y fragmentaria debido a la inercia economicista del crecimiento de la ciudad, las precarias condiciones sociales de la realidad nacional y la falta de la cultura de la participación, educación y planeación.

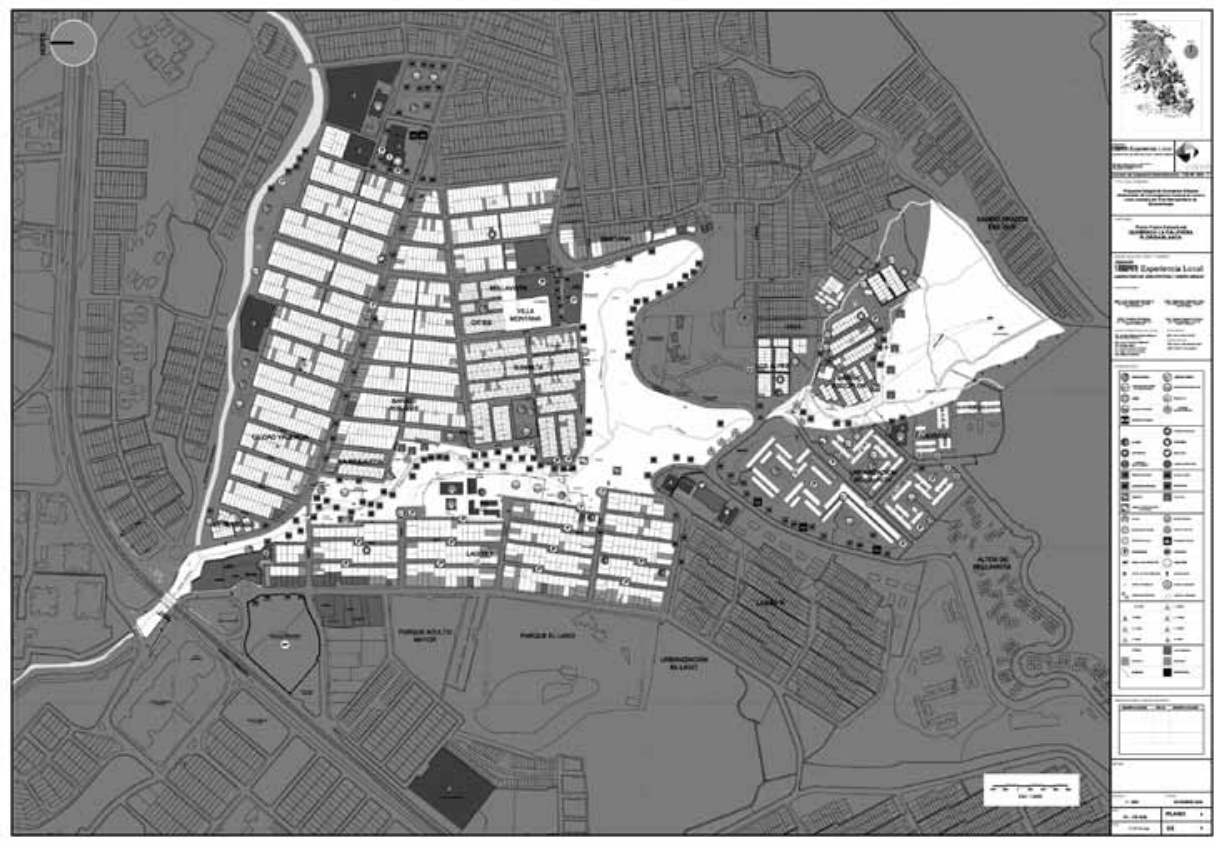


Esta situación ha dado como resultado un sentido de indiferencia creciente de los diferentes grupos humanos (políticos, administrativos, constructores, habitantes, académicos) hacia el interés por los patrimonios hídricos y ecológicos de afectación directa en los desarrollos de la ciudad. El estado de negación de esa realidad ha conducido a estos ecosistemas a experimentar la concentración de la contaminación, los focos de inseguridad, la desarticulación funcional y el detrimento físico y paisajístico de tales territorios.

Sin embargo, esta problemática aguda se convierte estratégicamente en la oportunidad de reivindicar la fragmentación urbana mediante la posibilidad de implantar un nuevo modelo de ciudad, que esté estructurado bajo las influencias y relaciones que provee la diversidad, cantidad y contacto directo de los trazados naturales de las quebradas y cañadas del Área Metropolitana con las personas, y que a pesar de las oportunidades perdidas y los daños irreparables en materia de articulación espacial, mantienen el espíritu de conservación del hombre, que también ha visto en ellas focos de desplazamiento, esparcimiento, contemplación e incluso desarrollo espontáneo. La misma espontaneidad con que se han gestado espacios públicos, circulaciones y puntos de encuentro requiere ser valorada y potenciada para establecer una comunión planificada y de seguridad de comportamiento futuro por medio de diseños de escenarios de vida de calidad que aprovechen el potencial natural de estos ecosistemas e incrementen la utilidad sobre las posibilidad de mejoramiento de la calidad de vida de los barrios y las personas que circundan directa e indirectamente estos ejes ambientales.

"El desarrollo es la acción que lleva al hombre a la satisfacción de las necesidades básicas y a un crecimiento armónico. Se plantea que el desarrollo debe darse de acuerdo a condiciones específicas de cada lugar y depende de las condiciones culturales y ecológicas de cada región". ${ }^{6}$

\section{Una propuesta más allá del imaginario de "Parque Lineal"}

La sensibilidad básica frente a las ecuaciones ambientales, urbanas y sociales, cuando se analizan a la luz del diseño urbano aislado tienen, por lo general, la tendencia a proyectar lo que se conoce como "Parque Lineal", en una visión reducida e irresponsable de las dinámicas y fenomenologías que acontecen en la influencia directa e indirecta de la gran cantidad de referentes zonales, barriales y comunitarios que implica el análisis de una quebrada o cañada. No es a partir de la disposición de trazados coordinados a los aislamientos normativos, por medio de senderos, mobiliario, iluminación y algún atributo agregado, como se da respuesta a la problemática fragmentaria que ha generado la existencia de estas quebradas y cañadas con el contexto urbano y social que históricamente se posicionó en su entorno. Si bien el imaginario de Parque Lineal hace parte de las propuestas, sólo cumple básicas funciones lógicas de experiencia espacial, que están, para el caso del proyecto de investigación, insertadas dentro de una consideración estructural de un Plan Urbano Integral para cada uno de los cinco lugares piloto. Este plan contiene una red integrada de espacio público que teje todas las relaciones históricas y las coordina con los nuevos planteamientos espaciales.

6 CUESTA, Op. Cit., p. 9

De la misma manera se proyectan "Conjuntos Urbanos", entendidos como puntos focales de actividad humana en donde los equipamientos $y$ las programaciones urbanas hacen parte de la configuración de un objetivo final de Renovación Urbana y búsqueda progresiva de un nuevo modelo de ciudad compacta. "Los ejemplos de ordenaciones ambientales más sobre- 
salientes son aquellos en los que esta relación directa entre el territorio y el asentamiento es manifiesta, aquellos que parece que tienen raíces ancladas a su territorio, como si de árboles se tratara". ${ }^{7}$ Los resultados de Diseño Urbano Integral, a partir de las premisas del Desarrollo Sostenible (balance ambiental, económico y social) se concluyeron por medio de las propuestas de ciudad para cada uno de los sectores en donde se realizó el estudio y que tuvo como objeto principal posibilitar una dinámica urbana propia y una adecuada relación con la superestructura urbana de la cual hacen parte a nivel zonal, municipal y metropolitano. Aspectos como el transporte público, el trabajo, la educación, la recreación, los servicios y el espacio público se fusionaron en los trazados que configuraron las siguientes particularidades para el experimento piloto:

La Cañada La Esperanza en el sector Norte de Bucaramanga, en la Comuna 2, representa uno de los principales problemas sociales de la ciudad, a partir de la falta de oportunidades para la población, la desintegración con las dinámicas urbanas fundamentales, el aislamiento cultural y las problemáticas de la estabilidad del terreno. El trazado natural de la cañada fracciona además las posibilidades de encuentro y diálogo de la comuna y concentra focos de problemáticas comunitarias. La propuesta articuló cuatro "Conjuntos Urbanos" equidistantes articulados a la red principal de espacio público y a la red vial básica. El primero aprovecha un terreno viable en el Barrio La Esperanza I y genera un núcleo de transformación de residuos, relacionando y mejorando simultáneamente un centro deportivo y una fuerte pendiente que los separa a través de tratamiento paisajístico y geo-tectura. El segundo propone la reubicación de un asentamiento subnormal llamado Nuevo Horizonte, e implanta allí un parque acompañado de equipamientos culturales. El tercero promueve la reubicación de una porción del barrio Villa Helena que sufre el hundimiento de sus casas, a través de la implementación de un bosque educativo que genera control social a partir de la educación ambiental en una biblioteca de escala barrial y un observatorio de flora y fauna.

Finalmente y como necesidad expresa de sus habitantes, el circuito se cierra con la proyección de un Centro de Servicios, en donde los habitantes de las Comunas I y 2 podrán realizar los procesos administrativos, institucionales y jurídicos sin tener que desplazarse hacia el centro de Bucaramanga.

El caso de la Quebrada El Loro, de Bucaramanga, es la formalización de una aspiración histórica de integrar un bosque urbano (seco-tropical) a dos grandes núcleos de actividad humana que están colapsados por falta de espacios públicos y equipamientos urbanos. La Ciudadela Real de Minas y los Barrios San Miguel y Candiles concentran una gran carga poblacional estática y flotante a partir de usos intensivos de vivienda, industria de bajo impacto y sobre todo por la existencia del complejo estudiantil denominado "La Calle de los Estudiantes”. La Quebrada incentivará el goce y la recreación pasiva posibilitando la experiencia en medio de un microclima urbano por medio de una intervención física respetuosa de la diversidad de flora y fauna del lugar por medio de sistemas constructivos y materiales no agresivos. La red de espacio público integrará el sector del Centro de la ciudad con la Ciudadela Real de Minas y se experimentarán cuatro conjuntos urbanos, progresivamente establecidos de oriente a occidente y de norte a sur así: Conjunto Urbano I, transición de la ciudad con el bosque, Conjunto Urbano 2, Equipamientos Culturales de apoyo a la Ciudadela Estudiantil, Conjunto Urbano 3, Torre de Educación Ambiental al interior del bosque como experiencia y control social y Conjunto Urbano 4, como complejo deportivo. 7 HIGUERAS, Ester. "Urbanismo Bio-
climático". Barcelona: Editorial GG, 2006. p. 19 


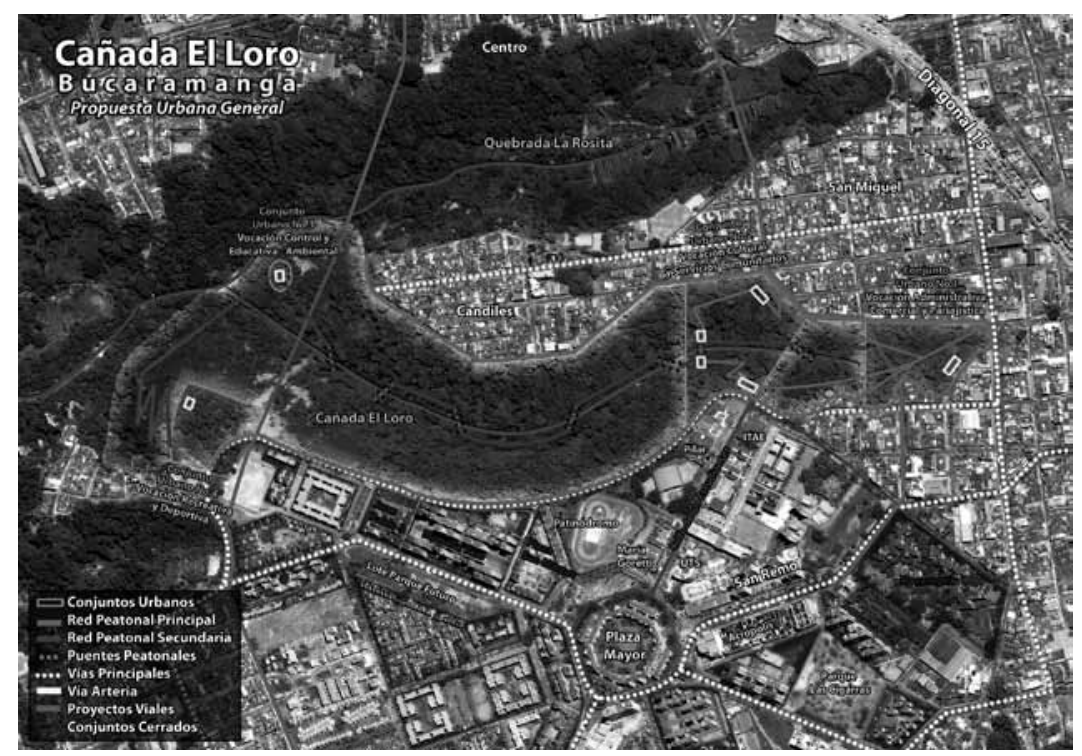

Foto 7. Plan Urbano Integral - Quebrada El Loro, Bucaramanga

La Quebrada Las Nieves, en Girón, articula la potencialidad del Centro Histórico con los barrios de Altos de la Campiña, La Campiña y Eloy Valenzuela, hasta desembocar en el Río de Oro, se propone la reubicación de la Plaza de Mercado Central y se establece allí el Conjunto Urbano de remate (No 3), que proviene del Conjunto Urbano No 2 que mezcla nuevos espacios públicos en espacios residuales existentes y promueve actividad comercial con la formalización del aplazado proyecto de calidad peatonal del Centro Histórico. La parte alta de la Quebrada contiene el Conjunto Urbano I, que posibilita la actividad cultural y recreativa. Por medio de tratamiento paisajístico reestablece las condiciones de contemplación de un sector con vastos terrenos de desarrollo incierto y alta densidad poblacional.

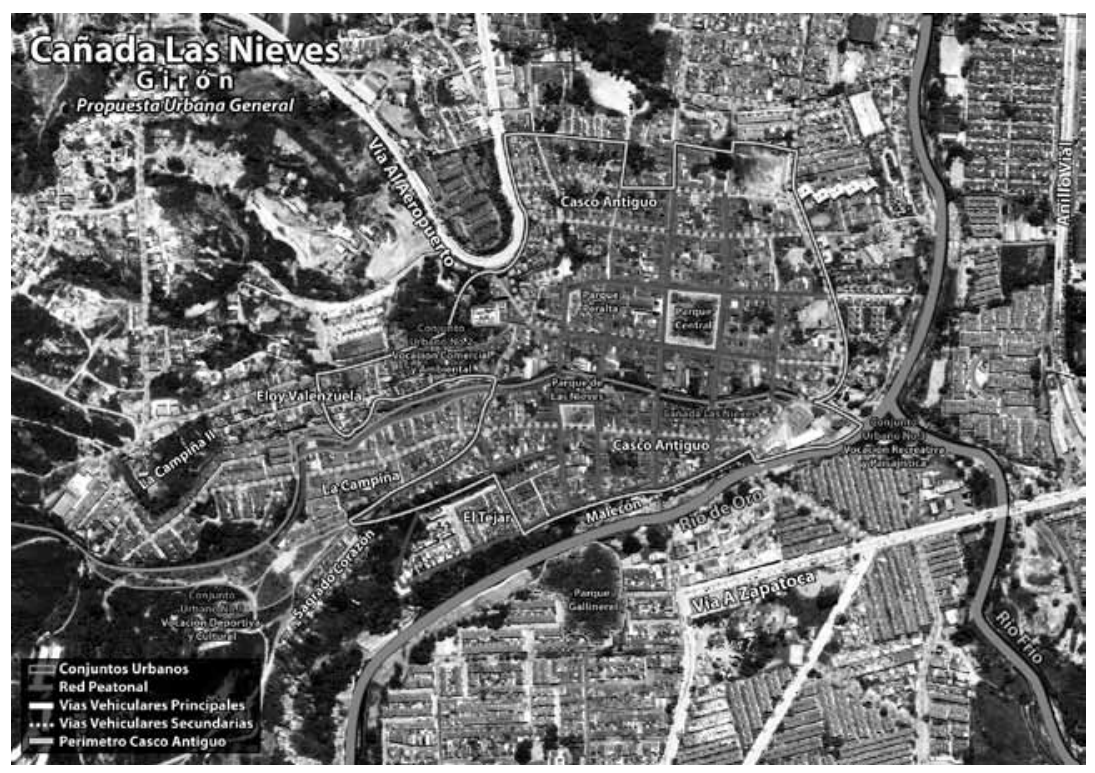


Las propuestas para las Quebradas La Calavera de Floridablanca y La Palmira de Piedecuesta comparten la intención de retejer las relaciones barriales disímiles que se encuentran con la existencia de conjuntos cerrados, conjuntos abiertos, invasión de las rondas de protección, asentamientos subnormales y principalmente con la precariedad del sistema de espacio público y los equipamientos urbanos mínimos para posibilitar dinámicas de vida comunitaria digna. Es así que, a partir de la reestructuración del sistema de espacio público, mejorado en términos funcionales, espaciales y materiales, se hace la propuesta de implantación de conjuntos urbanos en las zonas que el diagnóstico indicó como prioritarias para establecer lugares de encuentro cultural, ambiental, educativo y de aprovechamiento de potenciales zonas de desarrollo como el predio del Parque Recreacional el Lago de Floridablanca, en donde se implantará un Centro Cultural Metropolitano y un complejo deportivo que permite reubicar algunas canchas espontáneas que están al interior de la quebrada La Calavera.

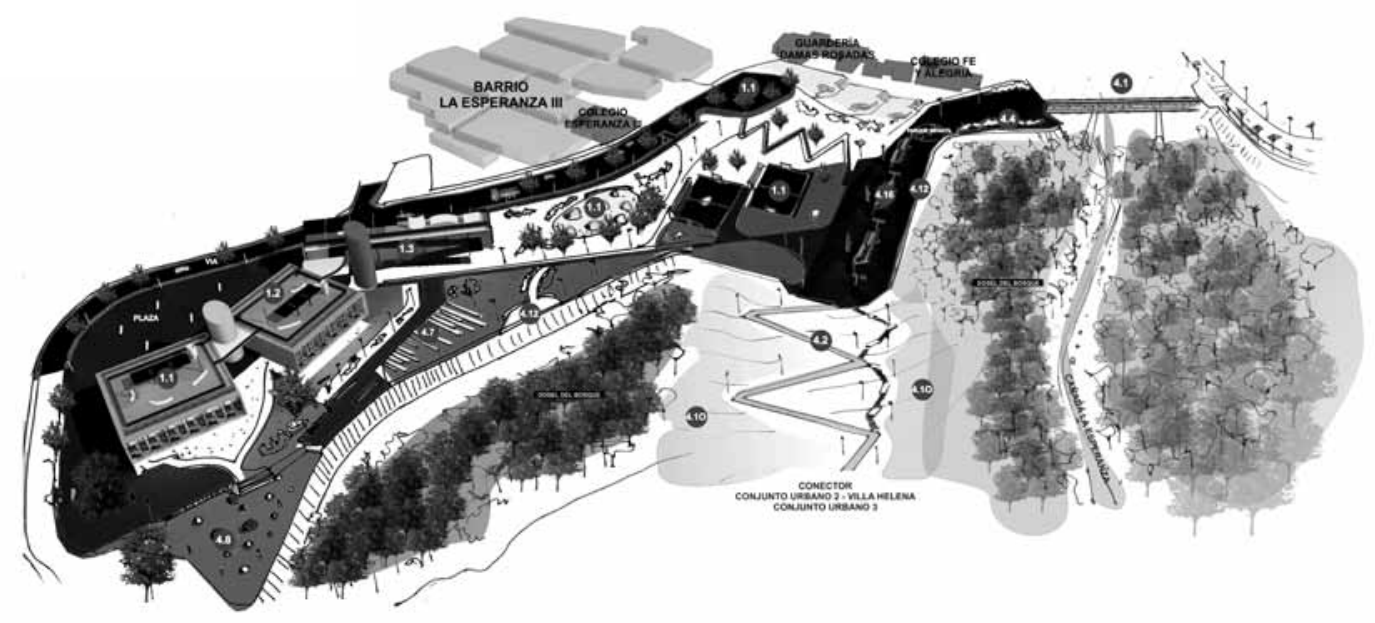

Perspectiva I. Propuesta Conjunto Urbano No 2 (Parque y Equipamiento Cultural) - Cañada La Esperanza, Bucaramanga

\section{Insumo concreto como punto de partida para la acción institucional, técnica, académica y comunitaria hacia el retejido urbano, ambiental y social}

Los resultados de la investigación, compilados en bitácoras y documentos de alcance social, urbano y ambiental, que refieren a un insumo planimétrico de anteproyecto de Diseño Urbano Sostenible, son el punto de encuentro y el fundamento de un proceso de socialización comunitaria e institucional para validar y continuar el proceso de búsqueda de reconfiguración del tejido de ciudad integral a partir de su Estructura Ecológica Principal. Se han superado todas las instancias institucionales relacionadas con la atención de las realidades que implican la acción coordinada sobre las zonas de afectación del proyecto y su abordaje responsable y coherente ha permitido el entendimiento rápido y la motivación para la integración y el aporte en sumatoria para generar el difícil salto regional de lo que se propone con lo que se ejecuta.

Es así que La Sociedad de Mejoras Públicas de Bucaramanga, la Gobernación de Santander, La Cámara de Comercio, Las Alcaldías de Bucaramanga y Girón, La Facultad de Salud de La Universidad Industrial de Santander y La Escuela de Topografía de las Unidades Tecnológicas 
de Santander, entre otras, han manifestado efectivamente su intención de hacer parte de las fases siguientes de la investigación y la proposición. La CDMB junto a CITU EXPERIENCIA LOCAL, continúan moderando el debate técnico y científico para formalizar la realización de la fase de profundización técnica, apropiación ciudadana e inserción del Plan General Metropolitano a los Planes de Ordenamiento Territorial y Planes de Desarrollo como prenda de respaldo para su asignación presupuestal en el futuro.

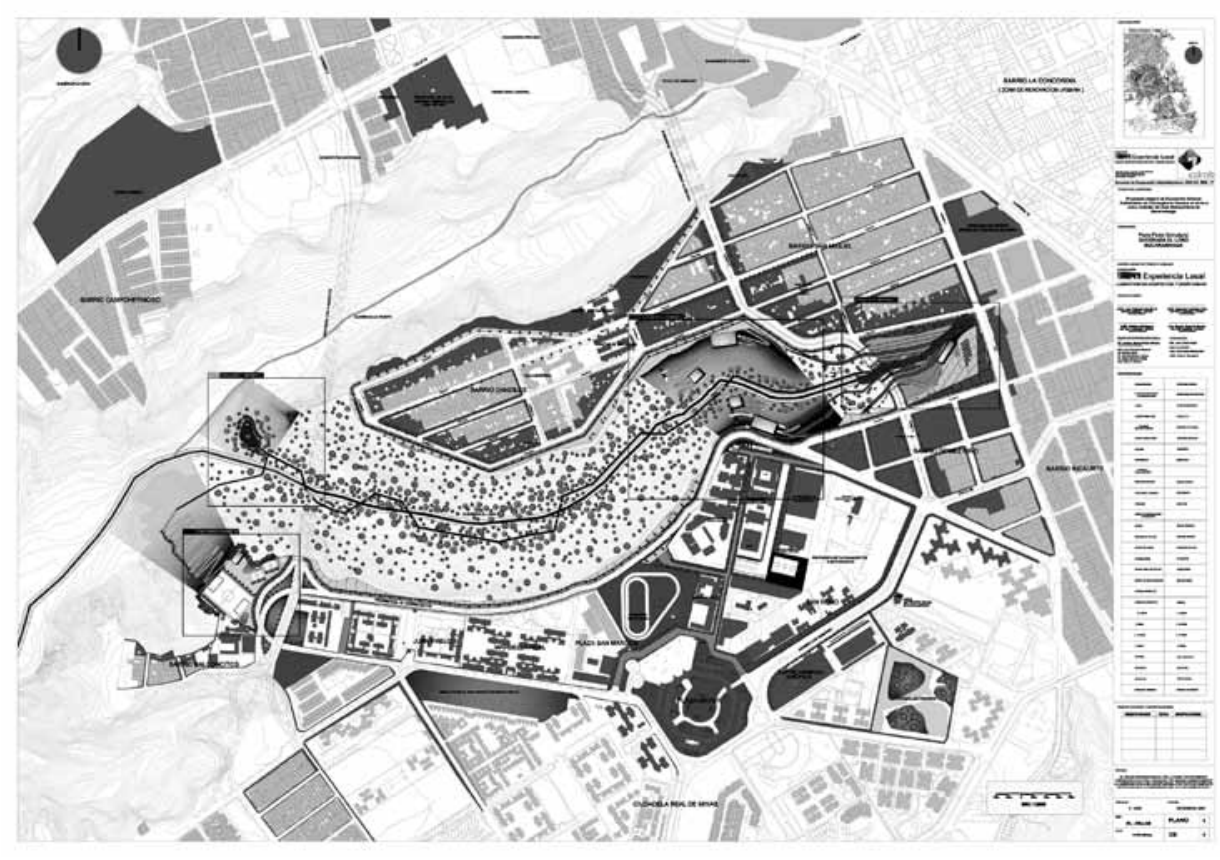

Plano 4. Propuesta Conjunto Urbano No. I (Transición Urbano y Equipamiento Administrativo) - Quebrada El Loro, Bucaramanga

La apertura de la investigación a todas aquellas instancias humanas que deseen contribuir al pensamiento, diseño, proyección, acción y seguimiento, es la estrategia para asegurar la legitimidad de la investigación, ya que poniéndola en debate permanente puede tener, a partir de sus moderadores y responsables, una focalización integral que asegura el éxito de la ejecución en una región en donde se acostumbran los procesos silenciosos, cerrados, privados y de mínima coordinación comunitaria. De la misma manera el proyecto propone la creación de un equipo interinstitucional que permita su desarrollo a partir de la estructuración de tres pilares: administrativo, técnico y de gestión. De esta manera se promueve una responsabilidad visible y permanente frente al experimento piloto de las cinco cañadas y su desarrollo.

De la misma manera se estudia permanentemente la posibilidad de proyección en otros lugares comunes del Área Metropolitana de Bucaramanga; que posibilitan evaluar los resultados existentes y focalizar los caminos de continuidad, para consolidar las alianzas que sean necesarias a nivel local, regional, nacional e internacional y ubicar el proyecto en un marco de realidad ejecutiva, que promueva la coordinación de los estudios técnicos de profundización y articule las competencias ambientales, sociales y espaciales como un solo comité de pensamiento, diseño y proposición. 
"Si bien casi todos coinciden que la investigación debe seguir adelante, también hay que reconocer que muchos de los sistemas y procesos ecológicos de la tierra son excesivamente complejos para ser cuantificados y representados en su totalidad."8

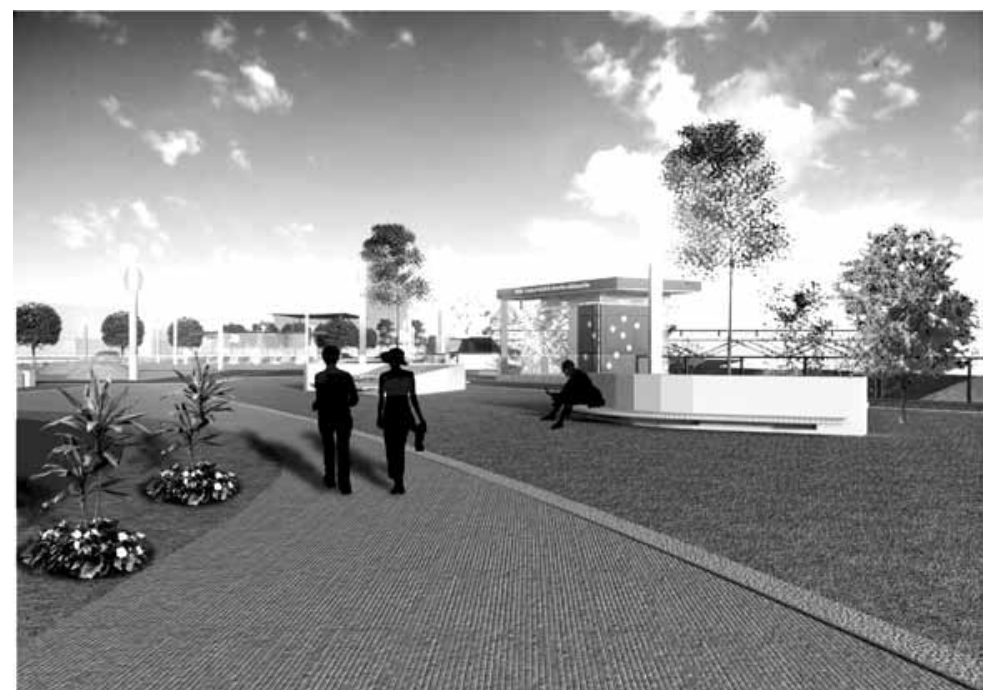

Perspectiva 2. Detalle Conjunto Urbano No 2 (Lugar de encuentro y manifestación) - Cañada La Calavera, Floridablanca

Como consideración final frente al abordaje del problema, para gestar líneas de desarrollo que permitan convertirlo en una oportunidad de retejer las complejas relaciones naturales, artificiales y humanas de la ciudad, la investigación generó el aseguramiento de un proceso obligatorio de fases dentro de un marco general de acción sin el cual el proyecto no puede ser adelantado.

Así se defiende la pertinencia de la acción científica sobre la inercia especulativa que desencadenó la dispersión y la baja calidad de vida urbana en torno a los patrimonios ambientales, la configuración de los barrios aislados, la generación de los espacios públicos vacíos y la contaminación de los ríos y quebradas. De no ser así, el proyecto podría caer en la dinámica de producción de obras físicas sin ninguna relación con su entorno y, en el peor de los casos, deteriorando los ecosistemas que se proyectan defender y articular por medio del proceso de investigación-acción.

De esta manera los resultados proyectivos de la investigación se ubican en el cuarto nivel después de tres precedentes fundamentales que van a iniciar trabajos a partir de la estimulación que el proyecto generó sobre las instituciones responsables y sobre la comunidad: I, Restauración de los ecosistemas a través de la implementación de obras de saneamiento ambiental e hidráulico; 2 , Adecuaciones hidráulicas y restitución de la habitabilidad segura en torno a las cañadas (Implementación de obras de control y mitigación de riesgos, alineadas a la propuesta general o compra de predios y planes de reubicación) y 3, Recuperación y preservación de las rondas de quebrada. 


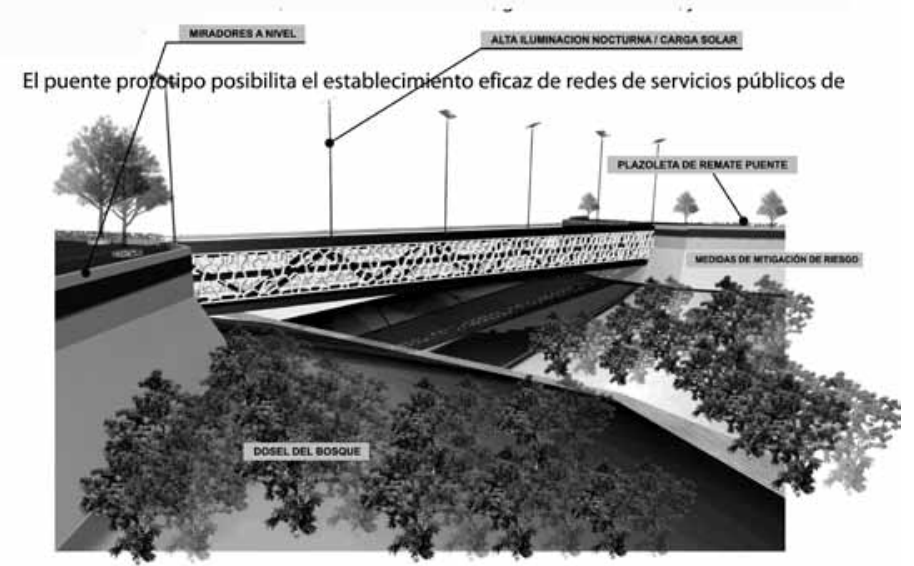

Perspectiva 3. Articulación a los espacios públicos y a las medidas de mitigación de riesgos.

Finalmente se concluye que la vocación hacia la integración de grupos científicos con instituciones públicas y la academia, para investigar en torno a la Estructura Ecológica Principal con relación directa al urbanismo, la sociedad, el medio ambiente y la cultura, es la semilla fundamental para proponer un nuevo modelo de ciudad que a partir de los patrimonios naturales que todavía existen, estructuren un marco de desarrollo sostenible que permita asegurar la calidad de vida de los habitantes del futuro en el Área Metropolitana de Bucaramanga, ya que las condiciones altamente patológicas y fragmentarias de la contemporaneidad no dan espacio para continuar la dinámica del aplazamiento, la resignación, la desarticulación institucional y la apatía ciudadana frente a los retos del entorno vital.

"Cuando le gente pierde su sentido de responsabilidad hacia el medio ambiente y se da cuenta que son meros tornillos en una máquina ¿Cómo pueden sentirse identificados con la comunidad? ¿Y cómo pueden ver alguna intención valiosa en cualquier planificación?"9

El reto se revela así como fundamental y aguarda el mismo rigor y pertinencia para las etapas de desarrollo posteriores. Sólo de esta manera se podrá reivindicar el diálogo humano para construir ciudades dignas y legítimas en medio de la diversidad humana y ecológica. y Participación. El caso de la Universidad de Oregón". Barcelona: Editorial GG 1978. p. 23

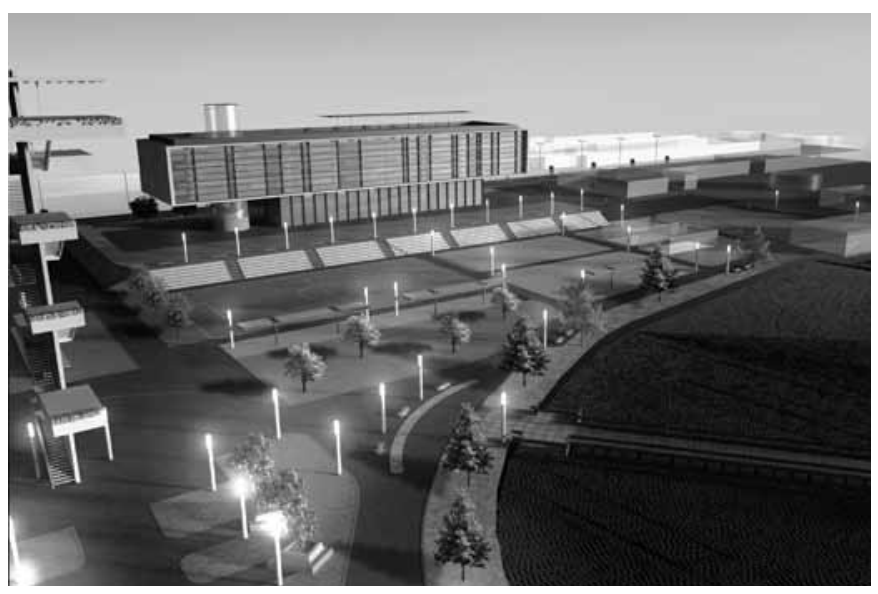

Perspectiva 4. Propuesta Conjunto Urbano No. 3 (Centro Cultural, Deportivo e integración comunitaria al Lago) - Cañada La Calavera, Floridablanca 


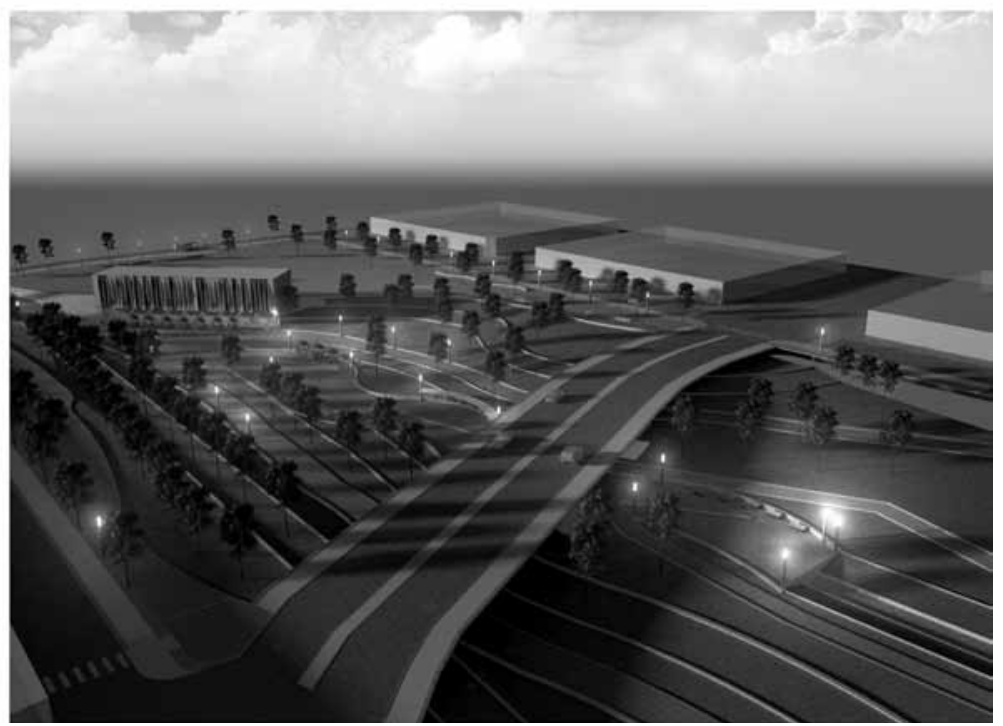

Perspectiva 5. Propuesta Conjunto Urbano No. I El Loro, Bucaramanga

\section{BIBLIOGRAFÍA}

PÉREZ, Edmundo. “Los cuerpos de agua en la ciudad”, Revista Escala I48. Bogotá: Ediciones Escala, 1989

HOUGH, Michael. "Naturaleza y Ciudad. Planificación Urbana y Procesos Ecológicos”. Barcelona: Editorial GG, 1998

CUESTA, Andrés. "Espacio Público y Desarrollo Sostenible”. Bogotá: Universidad La Salle, 2003

YEANG, Ken. "Proyectar con la naturaleza. Bases ecológicas para el proyecto arquitectónico”. Barcelona: Editorial GG, 1999

LEONEL, Francisco Javier. "Del derecho a la ciudad y su sentido dentro del espacio público como experiencia vivencial”. Bogotá: Universidad Piloto de Colombia, 2005

HIGUERAS, Ester. “Urbanismo Bio-climático”. Barcelona: Editorial GG, 2006

ALEXÁNDER, Christopher. "Urbanismo y Participación. El caso de la Universidad de Oregón”. Barcelona: Editorial GG, 1978 